\section{Valores de ferritina sérica em beta talassemia heterozigota}

\section{Serum ferritin levels in beta thalassemia carrier}

Isabeth F. Estevão ${ }^{l}$

Maria Cristina S. Souza ${ }^{2}$

Antonio J. Manzato ${ }^{3}$

Claudia R. Bonini-Domingos ${ }^{4}$

${ }^{1}$ Médica hematologista. Preceptora de Clínica médica da UFSCar ${ }^{2}$ Biomédica do Laboratório Unilab, São Carlos-SP

${ }^{3}$ Professor. Departamento de Ciências da Computação e Estatística Unesp, Campus de São José do Rio Preto-SP

${ }^{4}$ Bióloga. Professora do Depto. de Biologia, Unesp, São José do Rio Preto-SP

\section{Sr. Editor}

Estima-se que $1,5 \%$ a $3 \%$ da população mundial sejam portadores do traço talassêmico. ${ }^{1}$ No Brasil, a incidência depende da região avaliada. No estado de São Paulo acreditase que $2 \%$ dos indivíduos sejam portadores dessa alteração de hemoglobinas. ${ }^{2}$

Os heterozigotos geralmente são assintomáticos e o quadro hematológico se caracteriza por diminuição dos níveis de hemoglobina $(\mathrm{Hb})$, redução do volume corpuscular médio (VCM), sendo frequentemente confundida com anemia ferropriva. $\mathrm{O}$ diagnóstico diferencial é realizado pela avaliação dos índices hematológicos, análise morfológica do sangue periférico e quantificação das $\mathrm{Hb} \mathrm{A} 2 \mathrm{e} \mathrm{Hb}$ Fetal. ${ }^{3}$ A avaliação da ferritina sérica é fundamental para a discriminação diagnóstica.

Os níveis de ferro podem ser influenciados pelo aumento na absorção, pela baixa excreção e por mecanismos que regulem esse processo. ${ }^{4,5,6}$ A deficiência está relacionada a estados mórbidos, como alterações neurológicas, complicações obstétricas e do recém-nascido, incapacidade para o trabalho e imunodeficiência. ${ }^{5,6,7}$ Os grupos mais suscetíveis são as crianças entre 1 e 3 anos de idade, adolescentes, mulheres em idade fértil e idosos. ${ }^{8,9}$

Com o objetivo de comparar os níveis de ferritina sérica entre mulheres portadoras e não portadoras de beta talassemia heterozigota, avaliamos 137 mulheres no período de um ano, 63 com diagnóstico de betatalassemia heterozigota e $74 \mathrm{com}$ hemoglobinas normais (Hb AA). Esse foi um estudo retrospectivo, fundamentado em observação clínica de que portadoras de beta talassemia heterozigota apresentavam valores de ferritina aumentados. A seleção das mulheres foi aleatória e segundo a sua busca por consulta médica. Nesse momento foram orientadas sobre a pesquisa e, após o consentimento, incluídas no estudo. Os critérios de inclusão no grupo das não portadoras foram o nível de $\mathrm{Hb}$ igual ou superior a $12 \mathrm{~g} / \mathrm{dL}$ e o VCM entre 80 e $100 \mathrm{pg}$, e os de exclusão, para ambos os grupos, o uso de medicamentos à base de ferro há pelo menos um mês e a presença de doenças inflamatórias e/ou neoplásicas. As idades encontravam-se entre 10 e 49 anos.

O diagnóstico de beta talassemia foi baseado em hemograma (Pentras 120 Retic-Horiba $\mathrm{ABX}$ ), na quantificação das $\mathrm{Hb}$ A2 e Hb Fetal por HPLC (Bio-Rad) e na análise morfológica de sangue periférico. A dosagem de ferritina sérica foi realizada por quimioluminescência e esses resultados analisados estatisticamente pelo teste de Mann Whitney.

No grupo de mulheres não portadoras de talassemia beta minor, a idade variou de 10 a 48 anos, com média de 31,5 anos, e entre as portadoras de talassemia, de 12 a 49 anos, com média de 28, 48 anos. Os valores de Hb e VCM, utilizados para a separação dos grupos, estão descritos na Tabela 1 e evidenciam as diferenças inerentes à beta talassemia heterozigota.

O valor de ferritina sérica variou de 5,00 a 489,49 ng/ml com mediana de 51,90 nas portadoras de beta talassemia e de 7,09 a $170,00 \mathrm{ng} / \mathrm{mL}$ com mediana de 31,60 nas não portadoras. Valores acima de $150 \mathrm{ng} / \mathrm{mL}$ foram observados em sete (11\%) mulheres com talassemia e, em apenas duas (3\%) do grupo com $\mathrm{Hb} \mathrm{AA}$, encaminhadas para avaliação de hemocromatose. Em 10 (16\%) talassêmicas e em 20 (27\%) não talassêmicas foram encontrados valores abaixo de $20 \mathrm{ng} / \mathrm{ml}$ indicando deficiência de ferro, posteriormente investigada. A avaliação estatística dos níveis globais de ferritina sérica mostrou diferença significante entre os dois grupos $(p=0,0052)$ conforme ilustra a Figura 1.

$\mathrm{Na}$ beta talassemia heterozigota, geralmente a eritrocinética é normal, podendo ocorrer discreta diminuição da sobrevida dos eritrócitos e leve eritropoese ineficaz. Todavia, alguns estudos têm demonstrado a presença de sobrecarga de ferro nesses pacientes. ${ }^{10,11,12}$ A fisiopatologia dessa associação não está esclarecida e sugere-se um sinergismo entre as mutações nos genes que codificam proteínas relacionadas à absorção de ferro e a beta talassemia..$^{11,12}$ A diferença de ferritina entre os dois grupos estudados sugere maior poder
Tabela 1. Valores médios, mínimos e máximos de hemoglobina e VCM das mulheres avaliadas, portadoras de beta talassemia heterozigota e de Hb AA, para a definição dos grupos de estudo

\begin{tabular}{ccccccccc}
\hline & \multicolumn{3}{c}{ Hemoglobina $(\mathrm{g} / \mathrm{dL})$} & \multicolumn{3}{c}{ Volume corpuscular médio $(\mathrm{pg})$} \\
\hline Grupos & Mínimo & Máximo & Média & $\begin{array}{c}\text { Desvio } \\
\text { Padrão }\end{array}$ & Mínimo & Máximo & Média & $\begin{array}{c}\text { Desvio } \\
\text { Padrão }\end{array}$ \\
\hline Beta Tal & 9,2 & 13,2 & 11,04 & 0,94 & 57 & 71,6 & 63,7 & 3,2 \\
Hb AA & 12 & 14,6 & 12,9 & 0,67 & 80,5 & 93,7 & 86,4 & 3,3 \\
\hline
\end{tabular}




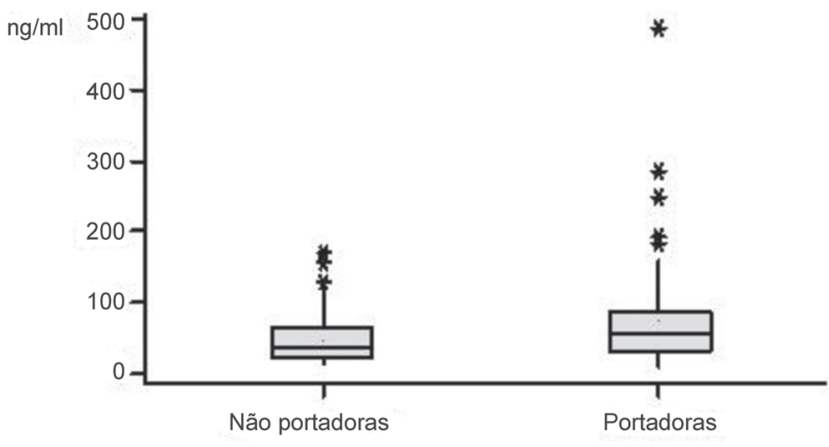

de absorção do ferro intestinal em portadoras de beta talassemia heterozigota. Em algumas situações, como em gestantes, crianças, adolescentes e mulheres que menstruam, podem acarretar uma vantagem seletiva. ${ }^{12}$ Por outro lado, quando não existe aumento das necessidades de absorção, há o risco do desenvolvimento de sobrecarga e, eventualmente, dano orgânico.

A heterogeneidade dos valores encontrados e a não correlação com os níveis de hemoglobina sugerem que esse aumento da absorção possa ser não só pela hemólise e eritropoese ineficaz desencadeada pela talassemia. Portanto, há necessidade de investigação de possíveis fatores genéticos e/ou ambientais que possam influenciar o mecanismo de absorção em talassêmicos do tipo beta heterozigotos.

\section{Abstract}

A low iron level, the commonest nutritional deficiency in the world, is a public health problem in developing countries. On the other hand, an excessive amount of iron is toxic, causing several organic dysfunctions, such as diabetes, cirrhosis, endocrinopathies and heart disease. Researchers have reported an association of iron overload with beta-thalassemia. The aim of this paper was to compare the serum ferritin levels of women with the betathalassemia trait. The results of serologic tests of 137 women of childbearing age were analyzed; 63 had the beta-thalassemia trait and 74 had $\mathrm{Hb} \mathrm{AA}$. In the beta-thalassemia carriers, the median ferritin value was $51.90 \mathrm{ng} / \mathrm{mL}$ and in the non-carriers $31.60 \mathrm{ng} / \mathrm{mL}$ $(p=0.0052)$. Levels of less than 20 and above $150 \mathrm{ng} / \mathrm{mL}$ were observed in $28 \%$ and $3 \%$ of the non-carriers and in $16 \%$ and $11 \%$ of the carriers, respectively. With these results it is possible to conclude that women in the reproductive age with the beta-thalassemia trait present higher ferritin levels in the northeastern region of São Paulo State. Further studies are necessary to clarify possible genetic and/ or environment factors which interfere in iron absorption. Rev. Bras. Hematol. Hemoter. 2010;32(2):171-172.

Key words: Beta-thalassemia; ferritins; iron deficiency.

\section{Referências Bibliográficas}

1. Galanello R, et al. Prevention of thalassaemias and other haemoglobin disorders. Nicosia: Thalassaemia International Federation Publications. 2003;1:190p.

2. Cançado RD, Jesus JA. A doença falciforme no Brasil. Rev Bras Hematol Hemoter. 2007;29(3):203-6.

3. Clark BE, Thein SL. Molecular diagnosis of haemoglobin disorders. Clin Lab Haematol. 2004;26(3):159-76.

4. Andrews NC. Molecular control of iron metabolism. Best Pract Res Clin Haematol. 2005;18(2):159-69.

5. Ganz T, Nemeth E. Iron imports. VI. Hepcidin and regulation of body iron metabolism. Am J Physiol Gastrointest Liver Physiol. 2006;290(2):G199-203

6. Pietrangelo A. Hereditary hemochromatosis. Biochim Biophys Acta. 2006;1763(7):700-10.

7. Booth IW, Aukett MA. Iron deficiency in infancy and early childhood. Arch Dis Child. 1997;76(6):549-54.

8. De Maeyer EM. Preventing and controlling iron deficiency in infancy anaemia through primary health care. Geneva: WHO; 1989.

9. Hallberg L, et al. Screening for iron deficiency; an analysis base on bone marrow examinations and serum ferritin determinations in a population sample of women. Br J Haematol. 1993;85(4):787-98.

10. Melis MA, Cau M, Deidda F, Barella S, Cao A, Galanello R. H63D mutation in the HFE gene increases iron overload in betathalassemia carriers. Haematologica. 2002;87(3):242-5.

11. Riva A, Mariani R, Bovo G, Pelucchi S, Arosio C, et al. Type 3 hemochromatosis and beta-thalassemia trait. Eur J Haematol. 2004;72(5):370-4

12. Martins R, Picanço I, Fonseca A, Ferreira L, Rodrigues O, Coelho $\mathrm{M}$, et al. The role of HFE mutations on iron metabolism in betathalassemia carriers. J Hum Genet. 2004;49(12):651-5.

Avaliação: Editor e dois revisores externos

Conflito de interesse: sem conflito de interesse

Recebido: 26/10/2009

Aceito após modificações: 01/02/2010

Unesp - Campus de São José do Rio Preto. Departamento de Biologia, Laboratório de Hemoglobinas e Genética das Doenças Hematológicas

Correspondência: Isabeth da Fonseca Estevão

Laboratório de Hemoglobinas e Genética das Doenças Hematológicas, Departamento de Biologia

Rua Cristóvão Colombo, 2265 - Jd Nazareth

15054-000 - Unesp - Campus de São José do Rio Preto-SP - Brasil Tel.:/Fax (55 17)3221-2392.

E-mail: isabeth@terra.com.br 